\title{
Erratum to: Engagement in Training as a Mechanism to Understanding Fidelity of Implementation of the Responsive Classroom Approach
}

\author{
Shannon B. Wanless • Sara E. Rimm-Kaufman • Tashia Abry • \\ Ross A. Larsen • Christine L. Patton
}

Published online: 11 December 2014

(C) Society for Prevention Research 2014

Erratum to: Prev Sci

DOI 10.1007/s11121-014-0519-6

The original version of this article unfortunately did not acknowledge sources of support. The research reported here was supported by the Institute of Education Sciences, U.S. Department of Education, through Grant R305A070063, R305B060009 (PI: Rimm-Kaufman), R305B090002 (PI: Pianta) to the University of Virginia. Any opinions, findings, and conclusions or recommendations expressed in this material are those of the author(s) and do not necessarily reflect the views of the U.S. Department of Education.

The online version of the original article can be found at http://dx.doi.org/ 10.1007/s11121-014-0519-6.

S. B. Wanless $(\bowtie)$

Department of Psychology in Education School of Education,

University of Pittsburgh, 5937 Wesley W. Posvar Hall, Pittsburgh,

PA 15260, USA

e-mail: swanless@pitt.edu

S. E. Rimm-Kaufman

Center for Advanced Study of Teaching and Learning Curry School

of Education, University of Virginia, 405 Emmet Street South,

Charlottesville 22904, VA, USA

T. Abry

T. Denny Sanford School of Social and Family Dynamics, Arizona

State University, 411 North Central Avenue, Phoenix, AZ 85004,

USA

R. A. Larsen

Department of Instructional Psychology \& Technology David O.

McKay School of Education, Brigham Young University, Provo,

UT 84602, USA

C. L. Patton

Graduate School of Education, Harvard University, 13 Appian Way,

Cambridge, MA 02138, USA 